\title{
EL ESTADO MODERNO EN CUANTO «ABSTRACCIÓN ARMADA ». ALGUNAS REFLEXIONES *
}

\section{The modern state as an armed abstraction. Some insights}

Germán Burgos Silva**

Recepción: 11 de septiembre de 2017. Aceptación: 29 de diciembre de 2017.

DOI: http://dx.doi.org/10.21017/Rev.Repub.2018.v24.a42

\section{RESUMEN}

El objeto de este artículo es el análisis crítico de la idea del Estado como detentador del poder público político, sosteniendo alternativamente que aquel cuenta con recursos de poder o ejerce el mismo en el marco de diversos actores que simultáneamente lo obedecen y cuestionan. Sostendrá a partir de la revisión y reflexión de cierta literatura proveniente de la ciencia política, la sociología y la antropología, que el Estado es un actor en buena parte abstracto que ejerce poder a partir del recurso a la coerción física o armada que es la que lo hace como tal típicamente un orden de poder político y que interactúa con otros actores de poder legales e ilegales en diversos juegos que merecen ser estudiados más en profundidad.

Palabras clave: Estado Moderno; monopolio de la fuerza; ficciones jurídicas.

\begin{abstract}
The Modern State plays a key role at national and international levels. Several law studies have documented how states are a sum of three public branches and they are produced by previous social contract between free and equal individuals. As a part of this approach, states possess political power. Previous studies of the state have not dealt adequately with the idea that power is not something that someone can have because power does not have a materiality in
\end{abstract}

* Artículo de reflexión vinculado al proyecto de investigación Las esferas de la globalización, del Grupo de Investigación Estado, Derecho y Territorio, avalado por Universidad Libre, Sede Principal.

** Doctor en Derecho, Summa Cum Laude, Universidad de Barcelona. Profesor de la Universidad Nacional de Colombia y de la Universidad Libre. Investigador asociado, según Colciencias. 
itself. It is not a thing to hold. This article seeks to understand and explain how the modern state is an abstract construction funded more in faith than in a social contract that have never existed. Additionally this article sustain that political power should be defined because of the use of coercion or monopolized violence instead the reference of public ends or the pacific solution of differences.

Key words: The Modern State; monopolization of violence; legal fictions.

\section{INTRODUCCIÓN}

Desde el derecho, el Estado se ha entendido como un conjunto de poderes públicos, especialmente concretizados en el legislativo, el ejecutivo y el judicial. Como parte de dicha aproximación, el Estado sería un centro de poder que en cuanto depositario de una soberanía previa, sería el mandatario especializado para encarnar los intereses públicos. Desde la idea de la soberanía popular o nacional, se plantea la existencia de un poder supremo, originario y autodeterminado, el cual no se puede ejercer de forma directa por la población, salvo de forma excepcional, de manera tal que son las instituciones del Estado, el soberano derivado, poder constituido, quien termina tomando decisiones soberanas, es decir, de poder. En otros términos, para el estudio jurídico del Estado, el poder lo detenta un soberano que no lo puede ejercer directamente de forma tal que lo entrega (como una cosa) a las instituciones estatales para que lo use (el poder) en su nombre. En últimas, el poder es una capacidad detentada por el pueblo o la nación en algunos casos, pero usada por las autoridades públicas.

La idea según la cual el poder se detenta, ha sido cuestionada sistemáticamente desde la ciencia política quien, entre otros, ve inaceptable la consideración de que aquel es algo cosificable y por tanto detentable y transmisible como plantea el derecho. Si bien se puede argüir que la construcción jurídica de los poderes públicos es algo interno del mundo jurídico y válido desde sus horizontes estrictamente normativos, es posible establecer a primera vista que los Estados han venido asumiendo incluso jurídicamente el eclipse de su centralidad en cuanto admiten a otros actores de poder social aun en el terreno de lo público.

Podemos encontrar así claras tendencias de desestatización de lo público a través del reconocimiento de actores con recursos de poder tan o más eficaces que los de los Estados y que se dedican a prestar servicios o desarrollar funciones públicas. En igual sentido, la emisión de normas estatales cuenta cada vez más con la interlocución con distintos actores sociales, no solo por razones democráticas sino considerando que cuentan con los recursos de poder para 
desobedecer o poner en cuestión la normatividad ${ }^{1}$. De otro lado, es muy normal hablar hoy de la crisis de la soberanía, entendida esta como la pérdida de capacidad para controlar a ciertos actores de poder internacional, sean organizaciones internacionales o multinacionales privadas, mientras simultáneamente campean lógicas secesionistas que amenazan con despedazar la integridad territorial del Estado, como en los casos de Cataluña, Escocia o la misma California.

No es entonces gratuito que desde hace algunos años se venga hablando de gobernanza, estado red, etc.; expresiones que dan a entender que el Estado interactúa con otros actores de poder social, pretendiendo convertirse en un catalizador y coordinador de un accionar colectivo en torno de ciertas agendas público-privadas.

El objeto de este artículo es el análisis crítico de la idea del Estado como detentador del poder público político, a partir de la síntesis de algunos planteamientos que sostienen alternativamente que aquel cuenta con recursos de poder o ejerce el mismo en el marco de diversos actores que simultáneamente lo obedecen y cuestionan. Sostendrá a partir de la revisión y reflexión de cierta literatura proveniente de la ciencia política, la sociología y la antropología, que el Estado es un actor en buena parte abstracto que ejerce poder a partir del recurso a la coerción física o armada que es la que lo hace como tal típicamente un orden de poder político y que interactúa con otros actores de poder legales e ilegales en diversos juegos que merecen ser estudiados más en profundidad.

El presente escrito se considera un trabajo de reflexión y revisión de la literatura, se funda en buena parte en la experiencia en la docencia universitaria de los cursos de teoría del Estado a nivel tanto de maestría como de doctorado y retoma fuentes secundarias de diverso tipo.

Para desarrollar el tema, el texto se divide en dos secciones. Una primera desarrolla que el Estado es en buena parte una organización abstracta fundada en una creencia colectiva más o menos extendida, aunque diferencial. En la segunda se abordará lo pertinente a las distintas lecturas que sostienen que el

1 Véase a título de ejemplo el Decreto 270 de 2017, que establece que con el fin de que los ciudadanos o grupos de interés participen en el proceso de producción normativa, a través de opiniones, sugerencias o propuestas alternativas, los proyectos específicos de regulación elaborados para la firma del Presidente de la República deberán publicarse en la sección de Transparencia y Acceso a la Información Pública del sitio web del ministerio o departamento administrativo que los lidere, por lo menos durante quince (15) días calendario, antes de ser remitidos a la Secretaría Jurídica de la Presidencia la República. 
Estado es una organización que tiene el poder, detenta recursos de poder y/o ejerce el mismo. Finalmente se sostendrá que en medio de diversas ideas en torno de lo público-político, el tema de la fuerza legítima es transversal a todos y fundamental para definir al poder como político.

\section{RESULTADOS}

\section{El Estado como construcción jurídica abstracta}

Un entendimiento extendido e inicial sobre el Estado, lo tiende a definir como un conjunto de instituciones públicas, ubicadas por encima de la sociedad y que son capaces de transformar la misma a nombre de la obtención de bienes político-públicos de diverso orden. Dicho de otra manera, el Estado se ha entendido como la suma de instituciones públicas dotadas de poder para atender las demandas de la sociedad, actuar sobre ella y gestionar lo público. A este entendimiento se debe agregar la concepción según la cual el Estado es una organización homogénea, compacta, sin fisuras y, por ende, dotada de una «voluntad» política (Gutiérrez, 2016; Bolívar, 2010)².

«La dimensión de Estado que se aborda no guarda relación entonces con la óptica de comunidad o de ordenamiento que tradicionalmente se ha entendido, sino que corresponde con el llamado Estado-aparato o Estado-Gobierno, entendido como "el complejo de órganos estatales con una subjetividad unitaria de poderes y deberes que se pone frente a los ciudadanos y otras personas jurídicas, públicas y privadas", o entendido de forma más breve "conjunto de organizaciones que ejercen el poder supremo (y que si forman un todo personificado se denomina Estadopersona), cuya personalidad jurídica le permite actuar en el "sentido de capacidad jurídica más capacidad de obrar mediante órganos» (Rosero, 2015: 28).

Como expresión de lo anterior, hoy por hoy es fácil constatar que dentro y fuera del mundo del derecho se afirma que el Estado es responsable, ausente,

2 «Como la unidad que integra a la nación en términos territoriales y sociales. Presupone la creación política de la comunidad imaginaria que da forma a la nación (Anderson, 1993) y el despliegue de dispositivos orientados a reafirmar la idea de la soberanía, centralización, autonomía, unidad y monopolización del control sobre la creación de reglas. Así, el Estado aparece como: [...] la imagen poderosa de una organización claramente definida y unificada, de la que se puede hablar en singular [...] como si fuera un solo actor con una motivación central que se comportara de una manera coherente para gobernar sobre un territorio claramente definido» (Espinal, 2014). 
indolente, carente de voluntad, capturado (García, 2010; Salamanca, 2008). En el mismo sentido, se exige, cuestiona, combate y demanda al Estado. Bajo todas estas referencias se da a entender la existencia de un ente todo poderoso, síntesis de lo público y encargado de un creciente e ingente número de tareas.

Con todo, asumir el carácter institucional del Estado antes anotado trae aparejado reconocer que este tiene una dimensión ficcional/abstracta o, en otros términos, no es posible ver, hablar e interactuar con las instituciones estatales, a pesar de que reiteradamente hablemos de ellas. Efectivamente, el mundo del derecho hace referencia a que aquel es una persona jurídica de derecho público, lo cual significa en el fondo que es una creación artificial y en este caso una ficción jurídica construida parcialmente desde el derecho ${ }^{3}$. Por lo demás, si bien los Estados son fácticamente la suma del comportamiento de múltiples personas, en virtud de la anterior ficción, se acepta que no son las personas las que operan, sino las instituciones abstractas. Así por ejemplo, cuando los integrantes de un Tribunal Supremo toman una decisión, incluso en medio de diversas diferencias, se anuncia y plantea que la decisión es del órgano, no de sus integrantes:

«En escritos acerca de las instituciones políticas hay muchas discusiones acerca de la naturaleza y el origen del Estado, que generalmente se representa como una institución que está por encima y por fuera de los individuos humanos que componen una sociedad, siendo uno de sus atributos algo llamado "soberanía". A veces se habla de él como si tuviera deseos (la ley se define como el deseo del Estado) o emitiera órdenes. En este sentido, el Estado no existe en el mundo fenoménico, es una ficción de los filósofos. Lo que existe es una organización, esto es, una colección de seres humanos individuales conectados por un sistema complejo de relaciones.» (Trouillot, 2001, p. 3).

Por tanto, decir que el Estado es un ente abstracto significa entonces que no tiene en buena parte una materialidad física, cosificable, empíricamente verificable, etc., sino que es una idea, una gran ficción a la cual le asignamos el

3 Para el caso colombiano y siguiendo a Rosero, se encuentra que «la personalidad jurídica del Estado se expresa ordinariamente a través de la Rama Ejecutiva, dado el carácter y las funciones de esta parte de la estructura del poder público (...)»141, que se encuentran algunas de ellas esbozadas en el texto constitucional y por excelencia en la Ley 489 de 1998 ». De hecho, la idea de que el Estado es una persona jurídica, proviene del Derecho privado, el cual en el código civil colombiano la define como una «una persona ficticia, capaz de ejercer derechos y contraer obligaciones civiles, y de ser representada judicial y extrajudicialmente». Art. 633. 
significado de ser omniponente (soberanía), homogénea y encargada de un ingente número de tareas que identificamos como intereses públicos, generales o nacionales. Dicho otra manera, no podemos ver, tocar e interactuar con el Estado, pero a pesar de ello le asignamos las funciones más críticas para la vida colectiva, sean estas la seguridad física, colectiva, la salud, la educación (Linera, 2010; Abrams, 1988).

Dicha no materialidad física del Estado, no niega sino aclara que su existencia es como una abstracción, como una idea, de manera similar a lo que es la moneda, la cual en sí misma es una representación colectiva de varios contenidos, pero en sí misma no encarna el valor de las cosas; o las palabras, las cuales son una representación de la realidad, pero no la agotan. Cuando hablamos de una abstracción no queremos decir que el Estado es un gran engaño inmaterial, sino que existe socialmente como algo que no podemos ver físicamente, pero en lo cual finalmente creemos, y de esta forma existe socialmente.

Esta existencia estatal en cuanto abstracción, siendo un aporte central de la antropología y de ciertas corrientes del marxismo, permite introducir igualmente que el Estado es producto en gran parte de la imaginación y/o la creencia (Harari, 2014). Entender que una población estatalizada deposita sus expectativas especialmente de seguridad futura (jurídica, alimentaria, física, social, etc.) en un ente que no es posible identificar empíricamente y en el cual, por lo demás, muchas personas tienen un alto nivel de desconfianza, puede ser entendido si apelamos a las creencias, es decir, a un sentido mítico religioso según el cual, si bien no lo podemos ver, asumimos que existe y por tanto no discutimos en qué términos se da su existencia.

«Esta perspectiva, de larga trayectoria en la literatura de orientación marxista y no marxista, parte de la premisa de que el Estado como tal no es una entidad empírica, sino un concepto analítico abstracto, lo que no significa que las relaciones de poder y de mando dejen de ser concretas y que influyan de manera profunda en la vida cotidiana de la gente» (Lagos, 2007, p. 17).

«Por eso para Supiot, la adaptación de los seres humanos a una suerte de personalidad jurídica, la cual les garantiza derechos y les impone deberes, es de carácter dogmático (basado en la fe) y proviene de una concepción de Estado como cuerpo místico característica de Occidente» (Molina, 2016).

En otros términos, identificar al Estado como una abstracción social, inevitablemente nos lleva a introducir que su sustento es un cierto tipo de fe en su existencia, al margen de su materialidad física y de su idoneidad. Creemos en 
la existencia del Estado de modo similar a como creemos en Dios y, por tanto, no nos importa no verlo, no interactuar con él de manera efectiva; y parafraseando la referencia bíblica, somos bienaventurados por creer aunque no lo veamos. Igualmente, de manera similar a Dios, hemos hecho de la creencia en el Estado, el foco de nuestras expectativas ligadas con lo que nos produce temor, sea la enfermedad, el dolor, el hambre, la pérdida de libertades, en últimas la incertidumbre del futuro ${ }^{4}$.

Ahora bien, parte de las creencias en torno de la abstracción estatal varían en el interior de la sociedad, estando representadas en consideraciones tales como su carácter represivo, neutral, sesgado, competente, fuente de riqueza, mecanismo de cambio social, resolutor de conflictos, defensor de la soberanía, etc. Dichas creencias que serían más sobre el papel real o figurado del Estado, tienden a estar asociadas a diversos enfoques teóricos, presentados en algunos casos como científicos o a la experiencia con los representantes del ente abstracto. Obviamente es posible que más de una de estas creencias convivan entre sí, incluso contradictoriamente.

$\mathrm{La}(\mathrm{s})$ creencia(s) en una entidad abstracta a la cual ligamos buena parte de nuestra vida colectiva ha(n) sido explicada(s) parcialmente por Harari (2014) apelando al papel que ciertos aspectos imaginarios tienen para la acción colectiva. En concreto, aquel sostiene que los humanos, quienes inicialmente vivíamos en pequeños grupos de cazadores-recolectores, donde la confianza se fundaba en el conocimiento mutuo, apelamos a crear progresivamente diversas abstracciones, tales como la moneda, la empresa, la nación y el Estado, a fin de poder cooperar con personas que no conocemos. En otros términos, el Estado es un invento social que permite la acción colectiva más o menos organizada entre personas que desconfían entre sí, pero que se necesitan mutuamente. Por tanto, la abstracción del Estado no sería una mera mentira colectiva, sino una forma para permitirnos interactuar con personas asentadas en un territorio, de forma permanente.

«En lo que los seres humanos somos especiales es en nuestra habilidad única para cooperar de forma flexible en grandes números. Muchas otras especies, desde las abejas hasta los chimpancés, cooperan; pero solo los miembros de la especie Homo cooperan de forma flexible con un número

4 En palabras de Schmit, «Todos los conceptos significativos de la moderna teoría del Estado son conceptos teológicos secularizados. Y no lo son solo debido a su evolución histórica, por haberse transferido de la teología a la teoría del Estado -al convertirse el Dios todopoderoso, por ejemplo, en el legislador omnipotente-, sino también con respecto a su estructura sistemática, cuyo conocimiento es preciso para el análisis sociológico de dichos conceptos» (Schmitt, 2006). 
indefinido de extraños... ¿Qué hace que los sapiens podamos cooperar de esa manera? Nuestra imaginación. Podemos cooperar con extraños porque podemos inventar historias sobre cosas que solo existen en nuestra imaginación -dioses, naciones, dinero- y difundirlas a millones de personas» (Harari, 2014) .

Si bien hasta ahora hemos sostenido que el Estado es en parte un ente abstracto fundado en la fe y creado como respuesta a la necesidad de acción colectiva entre extraños ansiosos frente a un futuro incierto, es obvio que la estatalidad tiene una existencia física, empírica; mas como se verá, no en cuanto tal. Como bien planteó Durkheim, lo que llamamos Estado hace referencia al accionar de ciertas personas; al uso y producción de ciertos documentos; a ciertas edificaciones generalmente ubicadas en el centro de las ciudades y a ciertos bienes muebles, dentro de los cuales cabe resaltar las armas (Durkheim, 1997).

«Veamos cómo se puede definir el Estado. Es un grupo de funcionarios sui generis dentro del cual se definen representaciones y actos de voluntad que involucran a la colectividad, aunque no sean el producto de la colectividad» (Lagos, 2007, p. 47).

Para el Derecho administrativo, esta separación entre el ente abstracto y la persona que actúa a nombre de él se expresa en la idea del agente de Estado, la cual en la práctica no solo reproduce la separación entre la abstracción y quien actúa sino que deja claro que el ente abstracto no puede actuar por sí mismo al ser una idea fundada en creencias ${ }^{6}$.

5 Para el marxismo, por su parte, el carácter abstracto del Estado ha sido visto como una forma de ocultamiento legitimador de las verdaderas relaciones de poder de clase que afectan a las personas y por tanto no serían una mera respuesta a la necesidad de acción colectiva entre extraños (Lagos, 2007).

6 La creación del sistema penal internacional, que dio lugar a la generación de la Corte Penal, cuyo gran referente fueron los juicios de Nuremberg, se basa en plantear que debe perseguirse a las personas que cometieron crímenes contra humanidad y de guerra, dado que las abstracciones, como el Estado, no comenten crímenes, cosa que sí hacen las personas: The Judgment of the Nürnberg Tribunal stated that "crimes against international law are committed by men, not by abstract entities, and only by punishing individuals who commit such crimes can the provisions of international law be enforced (Meron, 1995). A pesar de esto y como parte del impacto real de las ficciones jurídicas, en estos y otros casos, el Estado está sujeto a mecanismos de responsabilidad que funcionan y se expresan generalmente en reparaciones pecuniarias o no pecuniarias. Con todo, para que el Estado responda, se precisa que un conjunto de seres humanos tome decisiones en su nombre, otros ordenen gastos en su nombre y finalmente pidan perdón, en su nombre. 
Con todo, la existencia material de personas, papeles y cosas en que se expresa la acción de lo estatal afronta a su vez una dinámica adicional de abstracción, esta vez en cuanto hace al desconocimiento de sus realidades o condiciones materiales. Vía especialmente el derecho moderno y algunas de sus instituciones, las personas que trabajan para el Estado son servidores o funcionarios públicos; los documentos relacionados con su accionar van desde constituciones, leyes, actos administrativos, cédulas, tarjetas de identidad; los edificios donde se expresa son bienes públicos y las cosas que lo emblematizan son símbolos o fuerza legítima. Por esta vía, las cosas materiales no son lo que son, sino se convierten en expresión del ente abstracto y es por eso que tendemos a confundir esta con sus representaciones. Ocurre entonces una doble abstracción ligada con el Estado que le es finalmente complementaria; pues de un lado, el Estado es un ente abstracto, que precisa para tener vida material de personas y cosas de distinto tipo, pero siempre y cuando estas pierdan su materialidad y se consideren abstractamente.

En suma, aún a partir del derecho moderno, el Estado se ha entendido como una ficción jurídica, lo cual conlleva reconocer que es una creación artificial, pero sobre todo que no tiene una materialidad empírica como tal y que al ser una ficción es un ente abstracto, pero real; existe como abstracción. La asignación a una abstracción de las grandes tareas de lo público, que tienden a estar ligadas a la búsqueda de superar el temor al futuro vía la seguridad jurídica, social, física, etc., cosas que no siempre logra a cabalidad, depende en buena parte de un acto de fe, de una creencia cuasidivina. Parafraseando a Hobbes y su Leviatán, el Estado sería el equivalente a un Dios mortal. La finalidad de dicha abstracción se ha planteado en términos de permitir la acción colectiva entre extraños; esto en medio de otras abstracciones como el dinero, el mercado o la nación, que cumplen similar fin. En este contexto, el Estado tiene una materialidad, expresada en personas y cosas movibles e inamovibles, las cuales, sin embargo, no se consideran como tal, sino a las que se les asigna un valor jurídico como funcionarios o bienes públicos, entre otros. El abstracto Estado precisa de abstraer la realidad de lo que son sus medios de acción (personas, por ejemplo), para poder actuar.

Este abstracto, sin embargo, no es el producto de una mera creencia más o menos extendida vía diversos procesos, sino de manera parecida a su homólogo divino, se concibe como un ente todo poderoso, como centro de decisiones vinculantes para una población y en desarrollo de la idea de soberanía. La forma como desde diversos enfoques se ha abordado esta relación entre Estado y poder es la que se abordará a continuación. 


\section{El Estado y el poder}

En ese sentido, se pueden reconocer tres entradas. De un lado aquellas que sostienen que aquel tiene el poder de una forma por lo demás soberana. Por su parte, quienes apuntan que el Estado cuenta con ciertos recursos de poder estratégicos a nivel social. Finalmente, quienes sostienen que el Estado ejerce poder, siendo un actor al respecto, entre varios existentes. Según cada planteamiento, el alcance del poder del Estado es diferencial.

\subsection{El Estado como detentador del poder}

Comenzando con las tesis especialmente propias del derecho público democrático, el Estado sería el detentador de un poder derivado del pueblo o de la nación que lo tiene de forma originaria. El poder lo tendría el pueblo, la nación o aún Dios, vía la nación en algunos casos, y se lo entrega al Estado bajo la ficción jurídica del mandato o el contrato. El abstracto pueblo, nación o Dios, le da, a través de un hipotético contrato social, un mandato desde su poder a las autoridades del Estado y estas lo ejercen. Por esta vía los Estados tendrían un poder derivado de un ente más poderoso que ellos pero que generalmente por diversas razones no puede ejercer directamente. La expresión jurídica de lo anterior sería la figura del poder constituyente, pueblo o nación y el poder constituido, expresado en diversas instituciones estatales.

Visto de forma lo más precisa posible, los Estados detentan casi que plenos poderes derivados de una delegación del pueblo o nación, entendidos como soberanos y por ende supremos. Adicionalmente, tales poderes se expresan en competencias jurídicas de distinto tipo que dotan a las diversas instancias del Estado de poderes específicos según diversas áreas de acción. Así, a manera de ejemplo, la Corte Constitucional colombiana tiene el poder jurídico, como atribución, de decir la última palabra en materia del contenido de la Constitución, mientras las fuerzas armadas tienen la atribución jurídica de defender la soberanía.

A lo anterior, se une la generación de la concepción de un centro de decisiones vinculantes. En efecto, los Estados se conciben como núcleos de decisiones que deben ser obedecidas y por tanto simbólicamente tienden a concentrarse en capitales (nacionales o de departamento) y en edificios, que al menos en zonas de Occidente se construyen de manera grandilocuente y se tienden a ubicar en el «centro de las ciudades». Por tanto, dado que el poder se tiene, este se puede centralizar en determinados sitios, incluso en las estructuras federales.

Consciente o inconscientemente este entendimiento fuertemente jurídico, como se ha dicho, fue retomado a su manera por ciertas lecturas del marxismo que 
paradójicamente terminaron asumiendo que era posible la toma del poder, es decir, acceder a algo que está en el centro. Finalmente, la idea de centro y detentación del poder acompaña igualmente aquella de la homogeneidad en la medida en que el Estado se entiende como un ente unívoco, sin fisuras ni tendencias internas, ausente de conflictos y, como su nombre lo indica, algo estático y por definición no dinámico (Holloway, 2002).

«La idea marxista del Estado como centro de poder implicó dos cosas que claramente se contrapusieron a la perspectiva foucaltiana: que las luchas por el poder eran para apropiarse del Estado y conquistarlo o transformarlo (por lo tanto, el poder tenía un ámbito circunscrito y situado); y que el poder descendía de la cúspide del Estado hacia el resto de la estructura social» (Mussetta, 2009, p. 41).

En suma, bajo la primera de las entradas, el Estado es una organización de poder en cuanto detenta poderes derivados del pueblo, la nación o Dios; estos, a su vez, se presentan como atributos o competencias jurídicas que a su vez se envuelven simbólicamente en la idea de un centro irradiador de decisiones. Entonces, el poder se tiene, está en el Estado, el cual es ante todo un centro o conjunto de centros ${ }^{7}$. Al tener poder, las instituciones de Estado deben ser obedecidas.

Una aproximación como esta se puede cuestionar bajo varios argumentos. De un lado, al ser una construcción ante todo normativa para legitimar la existencia y accionar del Estado, se funda en abstracciones que terminan impactando negativamente en dicha legitimación. En efecto, la idea de una nación o pueblo soberano que precedió al Estado, no es empíricamente verificable, salvo excepcionalmente; lo mismo ocurre con la idea de un pacto o contrato social, generalmente inexistente; por su parte, el constructo pueblo, asumiendo la homogeneidad del mismo, reniega de la pluralidad tensionante que lo conforma y de las luchas de poder en el interior de la población. Por tanto, si bien normativamente se asume lo arriba indicado para legitimar la existencia del Estado, no es posible constatar que el pueblo o la nación vía un contrato social crearon el Estado y que este encarna de manera homogénea las expectativas de su supuesto creador.

7 En uno de los recientes paros cívicos en el departamento del Chocó, según informes de prensa, se denunciaba el abandono estatal. Sin definirse expresamente, este se entendía como que el centro, Bogotá, no había invertido suficientes recursos respecto de necesidades colectivas de esta región del país. Aquí la idea de centro queda palpable, dando a entender erróneamente que el Estado está en Bogotá y que en Chocó no existe estatalidad. De hecho, es posible intuir que para muchos chocoanos, el Estado está en Quibdó, mas no en el resto de los municipios. 
Ahora bien, aun aceptando normativamente las «metáforas» del pueblo, la nación y el contrato social como parte de una democratización necesaria del poder político, el enmascaramiento de la compleja realidad que esto conlleva termina por afectar el adecuado entendimiento de los problemas de legitimidad y obediencia que tienen los Estados. En efecto, por qué si el Estado es detentador de un poder delegado por el pueblo, sectores de la población se niegan a obedecer mandatos que jurídicamente provienen de ellos mismos como había planteado ya Rousseau a su manera. ¿Por qué si el Estado es depositario de una voluntad soberana, existen a su interior complejas tensiones entre diversos actores donde se disputan tanto diversos entendimientos sobre lo público como de apropiación privada de lo público?

Por tanto, la idea de que el Estado detenta el poder delegado del pueblo a través de un marco jurídico determinado es útil para legitimar al Estado y su derecho, pero, como es previsible, no permite explicar por qué dicho Estado no siempre es obedecido, cosa que pasa con la mayoría de Estados, o por qué en su interior hay diversas tensiones que no permiten tener claro que debe ser obedecido (Tyler, 2015).

\subsection{El Estado como detentador de recursos de poder}

Una segunda entrada nos plantea que la obediencia es el producto del acceso y uso de ciertos recursos socialmente estratégicos que estarían en manos, entre otros, de los Estados. Retomando a Tapia, los recursos de poder son mecanismos o entidades que permiten el establecimiento de relaciones de poder, que generalmente son escasos y compartidos en su valor por distintos actores, en parte por su escasez. Los mismos estarían en un estado potencial y dependiendo de la forma como son usados por los actores, estos devienen o no en medios idóneos para hacerse obedecer (Oro-Tapia, 2003).

Basándonos en Bobbio, es posible rastrear que el acceso al conocimiento y a la información genera un poder conocido como cultural o ideológico. Por su parte, la detentación de recursos económicos, los cuales son históricamente variables y hoy están monetizados o expresados en recursos naturales, tecnología, etc., genera los ámbitos propios del poder económico. Por su parte, la fuerza organizada de forma permanente sería el recurso propio del poder político como tal (Bobbio, 1989; Mann, 1997).

Basándonos en lo anterior, el Estado es una organización de poder en cuanto detenta, entre otros y fundamentalmente, tres recursos críticos socialmente y que le permiten obtener cierta obediencia. Es así como cuenta con información vía censos, catastros, bases de datos de diverso contenido, etc., que permiten sistematizar y validar información a partir de la cual se nos cobran impuestos, 
se puede restringir nuestra libertad o se permite o no el acceso pleno a ciertos derechos. Por su parte, los Estados, vía sus presupuestos, son grandes empleadores, lo cual tiene efectos tanto en quienes trabajan para él y también en sus familias, mientras es un gran contratista de obras públicas y un gran comprador. No por nada, el gasto público, aún en tiempos neoliberales, sigue siendo visto matizadamente como el gran animador del consumo interno. Finalmente, el Estado cuenta con recursos armados expresados en ejércitos de tierra, mar y aire; policías y órganos de inteligencia. Los mismos se caracterizan por su alto de nivel de organización y permanencia, al margen de la existencia o no de conflictos y guerras. La pervivencia de la fuerza como elemento de la estatalidad es tan clara que es casi imposible encontrar un Estado que haya renegado de esta para obtener obediencia.

Del sumun de estos tres recursos de poder, derivaría el poder del Estado, el cual, sin embargo, se caracterizaría adicionalmente de dos maneras. Mientras los recursos económicos e informativos no solo pertenecen al Estado, al ser compartidos con otros actores de poder tales como medios de comunicación, redes sociales, empresas, etc., el recurso a la fuerza se entiende como algo propio de los estados, monopolizado por estos. La fuerza no es privatizable, salvo bajo la autorización y control de los Estados. Adicionalmente, la exclusividad en el uso de la violencia institucionalizada y pretendidamente legítima daría al poder del Estado, superioridad respecto de otros actores de poder dado que los recursos de información y conocimiento y los económicos no podrían resistirse al uso de la fuerza. Bajo esta idea, el Estado, como producto de la monopolización antes indicada, se entiende como soberano, es decir, como poder superior al resto vía la coerción organizada y permanente (Weber, 1989).

Con todo, al hablar del poder político, este se ha asociado a los fines públicos, al uso de medios pacíficos para tramitar las diferencias, a lo realizado por ciertos actores organizados, etc. Sin embargo, estas diversas aproximaciones anotadas tienen un punto en común a saber, todas de una u otra manera aceptan o asumen la idea de la fuerza o la violencia institucionalizada. En efecto, la defensa última del interés público o general se hace usando la fuerza estatal; la tramitación pacífica de los conflictos descansa en última instancia en el uso de la violencia legítima; los actores políticos hacen del Estado su centro de atención en cuanto asumen explícita o implícitamente que este cuenta con recursos de coerción que permiten respaldar al final de cuentas sus preferencias o intereses (Crettiez, 2009).

Por lo demás, la centralidad de la fuerza como elemento definitorio de los Estados parece clara si constatamos que no existe ningún ente político así denominado que no cuente con órganos de fuerza permanentes para hacerse 
obedecer. El Vaticano mismo como forma sui generis de Estado cuenta con mecanismos de coerción especiales tales como la policía italiana y la guardia suiza. La misma Unión Europea desvaneció los monopolios de la moneda y el derecho de los Estados, pero dejó intacto el de la fuerza en cabeza de cada uno de ellos. Finalmente, la fuerza como elemento central de definición del poder político es la que trae aparejada la discusión sobre la legitimidad del mismo.

«Entonces, ¿cómo distinguir el poder político de otras variedades de poder? El poder político es el poder soberano, puesto que supraordina a todos los demás poderes. En efecto, en primer lugar, y a diferencia de los otros, es el único que puede imponer legítimamente su voluntad por la fuerza. En segundo término, es el único que está habilitado para tomar decisiones imperativas de carácter vinculante, por ende, obligatorias para todos los miembros de la colectividad. Esto implica que en última instancia el cumplimiento de tales resoluciones se puede llevar a cabo recurriendo al uso legítimo de la violencia» (Oro-Tapia, 2000, p. 7).

En comparación con la anterior aproximación, esta presenta varias ventajas. De un lado, al hablar de recursos, permite su abordaje más empírico en cuanto estos se pueden identificar, definir y hasta cuantificar, a diferencia de la idea según la cual algunos(as) tienen o no el poder. De otra parte, no son los meros recursos los que permiten obtener obediencia, sino su uso adecuado por los actores que los detentan en un sentido u otro, cosa que depende del valor que se le da a los mismos, el cual puede estar ligado o no con el tema de la escasez que los afecta. Finalmente, nos permite hablar de que ciertos recursos de poder se encuentran por fuera del ámbito estatal y por tanto permiten confrontarlo y resistirlo.

Con estas $\mathrm{u}$ otras ventajas, este entendimiento ha sido cuestionado bajo diversos planteamientos, que hasta cierto punto son extendibles a la primera tesis antes identificada. En primer lugar, sostener que el poder es algo que se detenta, vía el acceso a ciertos recursos o delegaciones, corporiza al poder, lo materializa de alguna forma, cosa que no es empíricamente verificable de forma plena y además transmite que si algunos tienen el poder como algo corpóreo, otros no lo tienen o lo tienen en menor proporción o cantidad, cosa igualmente no verificable. Adicionalmente, ocurre aquí una visión unilateral y superficial del poder en cuanto se mira desde quien lo ejerce y no desde quien dice o no obedecer; dicha unilateralidad por lo demás transmite la muy limitada idea según la cual, solo por tener poder o recursos de poder se obtiene la obediencia cuando es fácil determinar que no siempre el acceso a ciertos recursos o competencias conlleva ser obedecido, sino que además y, más claro aún, desconoce que no siempre se obedece, existiendo resistencias y cuestionamientos a quienes supuestamente tienen el poder. El poder, para existir, debe conllevar 
la obediencia en las relaciones sociales y, como acabamos de plantear, no por tener un supuesto poder se es obedecido, sino que contrariamente se puede ser resistido. Desde estas críticas se puede entender que aun cuando los Estados se entiendan como detentadores de recursos de poder y pretendan colocarse como el referente último vía la fuerza, diversas poblaciones, territorios y demás no siempre obedecen al Estado, lo resisten, lo cuestionan o buscan vivir al margen de él.

\subsection{El Estado como actor que ejerce el poder}

Finalmente, otra entrada sobre cómo entender el carácter del Estado como organización de poder, basada esta vez en los planteamientos de Foucault y Tapia ya citados, nos reitera que el poder no es algo que se detenta ni se encuentra en algún sitio, sino esta sostiene que el poder es una posición estratégica que se presenta a lo largo de diversas relaciones sociales de forma que aquel hace referencia a algo que se ejerce.

«El poder no es una institución, no es una estructura ni una fuerza de la que dispondrían algunos: es el nombre que se le da a una situación estratégica compleja en una sociedad dada » (Montbrun, 2010: 1). ${ }^{8}$

En otros términos, el poder es ante todo un tipo especial de relación social, que si bien se ha definido en términos negativos, es decir, afirmando que es algo que no se puede detentar, conlleva tener en cuenta diversos elementos analíticos. En primer lugar, si el poder es algo relacional, tiene que ver con las interacciones sociales entre seres humanos y en tal sentido la obediencia a cierto imperativo, mecanismo o mensaje puede ocurrir como puede no darse. Dado que estamos en presencia de relaciones, las mismas pueden darse en el sentido de obedecer o desobedecer de manera fluida y cambiante según ámbitos diversos de poder. Esto conlleva, en segundo lugar, admitir que nos encontramos en presencia de múltiples relaciones de poder a nivel social sea a

8 «De manera similar, Ferguson estima que el Estado no puede ser visto como una entidad que "tiene" o "no tiene" poder, o mejor, como un actor que "mantiene" o "ejerce" el poder, sino que este ha de ser considerado como una suerte de punto nodal desde el cual se coordinan y multiplican las relaciones de dominación (Ferguson, 2006: 281). Gledhill por su parte, nos invita a trascender la mirada del Estado como el locus central de poder, para ocuparnos del funcionamiento y difusión del poder a través de la sociedad (Gledhill, 2000: 44). Para estos autores, las prácticas y experiencias diarias se constituyen en el fundamento de la acción política, en virtud de lo cual, el poder ha de reconocerse en todos los niveles de la vida social, incluso en las relaciones más cotidianas, y no solo en los centros de control representados por el Estado y sus instituciones» (Martínez, 2016). 
nivel de la familia, la empresa, las organizaciones, dentro y fuera del Estado. El poder está regado en las relaciones sociales y por ende hay variado tipo de actores de poder, de forma tal que no es fácil afirmar su centralización en algún sitio, como suele ocurrir con el Estado. En tercer lugar y parafraseando a Weber, según Tapia, «todas las cualidades imaginables de un hombre y toda suerte de constelaciones posibles pueden colocar a alguien en la posición de imponer su voluntad en una situación dada» (Oro Tapia, 1999, p. 10). Sería así como el sexo, la altura, los uniformes, la belleza, la capacidad retórica, etc., son recursos que en determinado momento nos permiten ejercer poder sobre otros, de forma tal que adicionalmente estos son históricos, es decir, cambiantes en el tiempo. En cuarto lugar y como indicamos antes, ciertos recursos son considerados como más idóneos para poder ejercer el poder en cuanto son escasos y valiosos para un colectivo, sean estos el conocimiento, la información, el dinero o la fuerza9. Finalmente, las relaciones de poder tienden a ser asimétricas en cuanto al menos temporalmente nos encontramos en la situación de decisiones que pueden ser imperativas y/o manipuladoras para obtener obediencia (Oro Tapia, 1999).

«En suma, el poder es un concepto relacional. Esta afirmación hay que entenderla en dos sentidos. El poder es por una parte una relación social y no algo que se posea y por otra las entidades que se utilizan para establecer dicho tipo de relaciones, adquieren el estatus de recurso en la medida en que los otros la valoran como tal. En otras palabras, para que una entidad sea considerada como recurso de poder, debe ser valorada tanto por el actor " $a$ " como por el actor " $b$ ". Esto último implica que para que una entidad sea concebida como recurso de poder, depende de una valoración recíproca y no de una estimación unilateral» (Oro Tapia, 1999: 4).

Trasladando estos marcos al estudio del Estado en cuanto organización que ejerce poder, tendríamos que asumir entonces que este entra en relación con otros actores de poder que en algunos casos le obedecen, en otros resisten o en algunos otros instrumentalizan según sus intereses los términos de la obediencia. Adicionalmente, los Estados forman parte de diversas relaciones de poder internas y externas, sea con gremios, sindicatos, estructuras criminales, otros Estados u organizaciones internacionales que cuentan con diversos recursos (legales e ilegales) para discutir, cuestionar o resistir la estatalidad, pero también las relaciones de poder que van más allá del Estado como tal.

9 Aquí parece claro remarcar la relación entre el poder como el acceso a ciertos recursos y el tema del ejercicio del mismo. En efecto, no serían los recursos en sí mismos los que pueden generar obediencia, sino el uso de los mismos, el cual es dinámico y cambiante. En tal sentido, lo central sería el ejercicio. 
Los recursos con los que el Estado pretende ejercer poder tienden a ser económicos, de conocimiento y de coerción, siendo confrontado por actores que igualmente cuentan con recursos similares, incluso en algunos casos la fuerza. También a nivel social existe el importante recurso ligado a la acción colectiva organizada nacional o internacionalmente. Finalmente, el Estado forma parte de relaciones asimétricas, donde generalmente es este el que dice colocarse por encima de los demás actores de poder a través de la idea de soberanía y del uso de la fuerza; pero dado el carácter relacional, el Estado no solamente no siempre es obedecido sino en algunos casos obedece, a pesar de contar con la fuerza soberana. Esto último sería el caso del papel actual de ciertos organismos internacionales, empresas transnacionales, movimientos sociales globales, calificadoras privadas de riesgo, etc. o internamente ciertas élites $u$ organizaciones gremiales, sindicales e incluso delincuenciales.

Adicionalmente a lo anterior, reconocer que el poder no es algo que se detenta, sino que se ejerce, permite a su vez tener en cuenta que en el interior del Estado hay luchas de poder. En efecto, ya desde el liberalismo clásico se planteó que a fin de evitar abusos en el poder del Estado debía dividirse en su ejercicio a través del clásico tripartito ejecutivo, legislativo y judicial, lo cual llevaba aparejado a su vez pesos y contrapesos entre ellos, es decir, potenciales y reales tensiones y conflictos dados los controles mutuos existentes. Con todo, a esta clásica división que conlleva tensiones en el interior del poder del Estado, existen igualmente otro tipo de tensiones y luchas de poder dentro del Estado. Estas se dan entre organismos de control, respecto a otros ámbitos estatales; entre las entidades descentralizadas y los organismos centrales y entre organizaciones que han sido apropiadas de alguna manera por sectores de partidos políticos, universidades, representantes de regiones, corporaciones burocráticas sindicales o no; actores ilegales que han cooptado al Estado. Dada la existencia de distintos actores de poder, el Estado al actuar se muestra en su interior como un campo de lucha antes que como un actor homogéneo.

«El Estado, entendido como un campo, no es una entidad o un aparato fijo e inmutable: "su organización, objetivos, medios, socios y reglas operativas cambian [en una perspectiva histórica] cuando se alía o se opone a otros dentro y fuera de su territorio" ${ }^{10}$.

«La conclusión lógica de este enunciado es que las rivalidades y luchas entre los grupos dominantes, y entre estos y sectores subalternos, no presuponen un mal funcionamiento del Estado, su captura, debilidad o disolución, evidencian, por el contrario, las modalidades y formas de

10 Citado por Espinal, 2014, Op. cit. 
funcionamiento del campo estatal en contextos históricos determinados» (Espinal, 2014, p. 7).

Esta entrada entronca muy bien con la noción actual de gobernanza según la cual, el Estado no tiene hoy por hoy la capacidad de imponerse de forma unilateral y dominante sobre la sociedad, sino que su tarea es ante todo coordinar la gestión de actores públicos y privados en la provisión de ciertos bienes y servicios de carácter general. La idea de red sin centralidad sería algo más realista y cercano al funcionamiento real de los Estados actualmente (Mayntz, 2001).

De hecho, como bien ha planteado la antropología del Estado, este es en parte un conjunto de prácticas diversas y caóticas que actúan de manera simultánea y no siempre coordinada. Finalmente, una de las quejas más recurrentes a la hora de evaluar políticas de Estado es la ausencia de coordinación y solapamiento entre diversos organismos, aspecto que podría considerarse como expresión de tales luchas de poder ${ }^{11}$.

Como crítica a los anteriores planteamientos se puede sostener que si bien el Estado no detenta el poder como centro del mismo, para una parte importante de la población sigue siendo el referente central de demandas y reivindicaciones y por ende, de una u otra manera, guarda una centralidad simbólica que no siempre es coherente con su debida capacidad. Por lo demás, si el poder está en todas partes y no hay jerarquías entre los diversos actores de poder, se debería concluir que el poder no está en ninguna parte, desconociendo además las diversas jerarquizaciones que en la práctica existen entre diversos actores de poder (De Sousa, 2010 ). ${ }^{12}$

A pesar de estas críticas, la afirmación según la cual el Estado es un actor que ejerce poder, aparece como un marco analítico más que potente para poder estudiar histórica y actualmente el funcionamiento real de los Estados. Es decir, antes que centros de poder que detentan una soberanía delegada de un sujeto abstracto llamado pueblo o nación y que en tal sentido tienen una voluntad unívoca, clara y consistente, los Estados realmente existentes son actores de poder que interactúan con otros actores del mismo tipo, en el

11 El Estado ha de entenderse como «una colección de prácticas descentradas sin una agencia central o un proyecto medular» (Martínez, 2011).

12 «El Estado, desplazado en su existencia unitaria y uniforme, permanece sin embargo como una instancia central (como un proceso constante de centralización) de las relaciones de gobierno: régimen móvil de gubernamentalidades múltiples, campo estratégico en que se despliegan las diversas prácticas de gobierno, tanto públicas como privadas, en su compleja articulación» (Romannutti, 2014). 
marco de múltiples relaciones y a través de diversos recursos. Por esta vía, es importante entender que los estados no siempre son ni serán obedecidos y contrariamente tienden a ser resistidos y desobedecidos por actores legales e ilegales dentro y fuera de sus territorios. La situación es aún más compleja si tenemos en cuenta que en los Estados hay luchas de poder, algunas de ellas buscadas vía ciertos arreglos instituciones como la división de poderes, que dificultan mucho hablar de una voluntad política y unívoca de soberanía. Lo último a resaltar es que la reciente entrada aquí expuesta es la que confronta con mayor claridad aquella cultivada y promovida desde el derecho constitucional.

\section{CONCLUSIONES}

El presente texto de reflexión buscaba controvertir la idea según la cual el Estado tiene y detenta el poder, que si bien es propia del mundo del derecho es extendida a otros ámbitos disciplinares. Desde el derecho entonces es generalmente aceptado que el Estado tiene el poder como el producto de un mandato contractual proveniente de un conjunto de individuos libres e iguales que le antecedieron. El Estado entonces detenta un poder que por lo demás extiende sus atribuciones a través de un marco de competencias jurídicas. En una línea parcialmente similar pero diferente se planteó que la detentación del poder haría referencia a ciertos recursos usufructuados por el Estado y correspondientes a la información, los recursos económicos y los relativos a la violencia, de forma tal que la obediencia sería el producto de estos teniendo en cuenta además la centralidad de la fuerza como recurso capaz de imponerse al poder económico o del conocimiento.

Estos dos enfoques se han cuestionado en cuanto corporizan el poder al considerar que este se tiene o detenta; al visualizar el mismo desde el punto de vista de quien lo tiene, negando su bilateralidad mínima y no incluyendo el ámbito de las resistencias y cuestionamientos al poder, incluso el del Estado. No porque el Estado tenga supuestamente el poder, este es obedecido por la población.

A partir de críticas como las anteriores se planteó que, desde una mirada más compleja, el Estado es un actor de poder entre otros que existen socialmente a nivel nacional e internacional. Si bien la idea de que el Estado tiene una pretendida centralidad, esta hace aguas en cuanto los Estados no son capaces de hacerse obedecer por otros actores de poder en cuanto el poder es resistido y adicionalmente ejercido de forma bilateral, del Estado hacia otros actores de poder y de estos sobre el Estado. Finalmente, una aproximación al Estado como actor que ejerce poder permite visualizar que en el 
interior del mismo hay diversas luchas formales e informales que cuestionan la idílica idea de aquel como una organización homogénea y con una voluntad unívoca.

Por otra parte, la conceptualización del Estado como organización de poder político ha sido entendida a la luz de ciertos fines (intereses públicos, tramitación de diferencias), de ciertos actores (los políticos) y de ciertos medios, tales como la fuerza permanente, organizada e institucionalizada. En medio de estas diversas aproximaciones, aquí se ha sostenido que el medio de la fuerza legítima es el que mejor define el carácter político del Estado en cuanto es el sustento transversal de los demás entendimientos antes indicados.

\section{REFERENCIAS}

Abrams, P. (1988). Notas sobre la dificultad de estudiar el Estado. Journal of Historical Sociology, 1(1), 58-89.

Bobbio N. (1989). Estado, gobierno y sociedad. México: FCE.

Bolívar, I. J. (2010). Formación del Estado y biografía de las categorías. Nómadas, (33), 93-108.

Crettiez, X. (2009). Las formas de la violencia. Buenos Aires, Argentina: Waldhuter.

De Sousa Santos, B. (2010). Descolonizar el saber, reinventar el poder. Montevideo, Uruguay: Ediciones Trilce.

Durkheim, E. (1997). Las reglas del método sociológico (Vol. 86). Ediciones Akal.

Espinal, M. A. A. (2014). La definición del campo estatal y su relación con la guerra civil: un horizonte teórico. Estudios Políticos, (45), 135-157.

García-Villegas, y M., Revelo, J. E. (2010). Estado alterado. Clientelismo, mafias y debilidad institucional en Colombia. Bogotá. Colombia: Dejusticia.

Gutiérrez, F. (2016). Construcción, Deconstrucción y reconstrucción del Estado. Una revisión de la literatura nacional e internacional. En: C. López, (Ed.), jAdiós a las Farc! ¿Y ahora qué?, 1.a ed. Bogotá, Colombia: Debate.

Harari, Y. N. (2014). Sapiens. De animales a dioses: Una breve historia de la humanidad. Barcelona, España: Debate.

Holloway, J. (2002). Cambiar el mundo sin tomar el poder: el significado de la revolución hoy. Madrid, España: El Viejo Topo. 
Lagos, M. L., y Calla, P. (Eds.). (2007). Antropología del Estado: dominación y prácticas contestatarias en América Latina. La Paz, Bolivia. Cuaderno de Futuro nro. 23. Plural editores.

Linera, Á. G. (2010, junio). La construcción del Estado. En Conferencia magistral. Realizada por la Facultad de Derecho de la Universidad de Buenos Aires, UBA. Buenos Aires, Argentina.

Mann, M. (1997). Las fuentes del poder social, II. Madrid, España: Alianza Editorial.

Martínez, S. P. (2011). Revisitando al Estado: límites y posibilidades de las aproximaciones contemporáneas al estudio del ordenamiento estatal. En: X Congreso Nacional de Sociología. Universidad ICESI.

Mayntz, R. (2001). El Estado y la sociedad civil en la gobernanza moderna. Reforma y democracia, (21), 7-22.

Molina, A. (2016, 26 de junio). La dictadura del derecho. Razón Pública. Recuperado de http:/ / razonpublica.com/index.php/lectura-p\%C3\%BAblica/9531- la-dictadura- del-derecho.html

Meron, T. (1995). International criminalization of internal atrocities. American Journal of International Law, 89(3), 554-577. doi:10.2307/2204173

Montbrun, A. (2010). Notas para una revisión crítica del concepto de «poder». Polis (Santiago), 9(25), 367-389.

Mussetta, Paula. (2009). Foucault y los anglofoucaultianos: una reseña del Estado y la gubernamentalidad. Revista mexicana de ciencias políticas y sociales, 51(205), 37-55. Recuperado de http://www.scielo.org.mx/scielo.php?script=sci_arttext\&pid= S0185-19182009000100003\&lng=es\&tlng=es

Oro Tapia. L. R. (1999). La idea del poder. Documento de discusión nro. 23. Instituto de Ciencia Política de la Universidad de Chile.

Oro Tapia, L. R. (2000). Tres aproximaciones a la idea de política. Boletín Jurídico de la Universidad Europea de Madrid, (3), Madrid, España.

Oro Tapia, L. R. (2003). ¿Qué es la política? Santiago, Chile: RIL Editores.

Romanutti, H. G. (2014). El Estado según Foucault: soberanía, biopolítica y gubernamentalidad. Utopía y Praxis Latinoamericana, 19(66), 53-66.

Rosero Arce, S. H. (2015). La personalidad jurídica de las entidades públicas: una simple denominación técnica dada desde el derecho positivo (Doctoral dissertation). Universidad Nacional de Colombia, Bogotá, Colombia. 
Salamanca, L. J. G., Salcedo-Albarán, E., de León-Beltrán, I., y Guerrero, B. (2008). La captura y reconfiguración cooptada del Estado en Colombia. Bogotá, Colombia: Avina, Grupo Método.

Schmitt, C. (2006). Teología política (Vol. 2). Editora del Rey.

Trouillot, M. R. (2001). La antropología del Estado en la era de la globalización. Encuentros cercanos de tipo engañoso. Current Anthropology, 42(1), 137-139.

Tyler, T., y Correa, C. P. (2015). La obediencia del derecho. Bogotá, Colombia: Ed Uniandes.

Weber, M. (1998). El político y el científico. Buenos Aires, Argentina: Alianza. 